\title{
The concrete-based high performance decorative material for severe climatic conditions
}

\author{
Sofia Bazhenova ${ }^{1}$ and Anton Pilipenko ${ }^{1, *}$ \\ ${ }^{1}$ Moscow State University of Civil Engineering, Yaroslavskoeshosse, 26, Moscow, 129337, Russia
}

\begin{abstract}
This paper presents experimental investigations on the development of high performance colored concrete-based decorative materials for regions with severe climatic conditions. The main idea of the research is the creation of concrete-based material with admixtures, consisting of mechanically activated crushed concrete fines. In this context, the influence of mechanic-chemical activation of admixture and coarse aggregate to the properties of decorative concrete were examined. Firstly, main features of the severe environment, which affects the decorative exterior materials, and methods of protection against them are shown. The optimized concrete mixes and their main properties are presented based on analysis of these features. The main areas of the usage of designed concrete-based materials are specified in the Siberian and Far East regions of Russian Federation.
\end{abstract}

\section{Introduction}

The development of Russia's northern and eastern regions, which are characterized by severe climatic conditions, according to the Government order of July 5, 2010 № 1120-r "The Strategy of socio-economic development of Siberia 2020", due to the construction of new and reconstruction of the old transport network, energy network, information and telecommunication infrastructure of Siberia, residential and industrial projects. The concrete and reinforced concrete, characterized by their versatility and increased performance, could be the most widely used building material in these conditions.

At the same time one of the most important problems of modern construction in the Northern Russian regions with particularly severe climatic conditions, along with high durability of exterior finishing materials and their long-term operational reliability, is to provide high decorative characteristics [1]. The color and texture of decorative materials are directly related to the psychological comfort of people living in severe environments, and could have a positive impact on human health[2-4]. Currently, in the construction and reconstruction of these towns, traditional materials and materials, adapted to the severe climatic conditions by addition ofadmixtures of various chemical and mineralogical compositions and roles, are mainly used. The usage of decorative materials is based on proven technologies, developed in 1950-80's [5-7].Besides low capillary porosity,

\footnotetext{
${ }^{*}$ Corresponding author: pilipenko.ans@gmail.com
} 
decorative materials should also meet the specific requirements on the quality of the front surface of the windshield and to ensure the absence of snow accumulation on the surface of buildings. Traditional materials based on cement binder could not always meet these requirements, but their main disadvantage is the relatively low durability. This happens due to the presence of extensive network of capillary porosity, hairline cracks and other structural defects which are formed at the stage of manufacture and during the life cycle.

The concrete casting in the Northern regions has special techniques. However, the manufacture of decorative concrete units(such as tiles, plates, decorative fixtures and so on) does not require any radical change in their technology, because these units are produced in warm workshops and are not exposed to severe environmental factors.

The main feature of the Northern regions of Russia is the presence of a sufficient number of heavy industry plants and, as a consequence, a large number of silicate waste (ash and slag from power plants and steel plants, etc.). A considerable amount of concrete waste is generated as a result of the demolition and reconstruction of residential and industrial buildings. This type of waste is basically made from cement minerals and contains un hydratedcement particles in its composition. Depending on the method of grinding, the concrete waste may have different properties which make it optimal for use in certain materials [8]. All of these types of industry waste have been studied for possibility of their usage in decorative concrete previously [9].

The decorative effect of decorative concrete products could be created in various ways [10].The most preferred method in technology of colored waste-and-concrete-based products is the joint mechanochemical activation of crushed concrete fines together with a mixture of pigment and binder [11,12].

Thus, the creation of high-performance concrete-based decorative materials for regions with severe climatic conditions could be economically attractive. This could be achieved by development of high-performance concrete with high compressive strength (60-120 MPa and above), frost resistance (more than the F400), water-resistance (more than the W12), low abrasion (less than $0.4 \mathrm{~g} / \mathrm{cm}^{2}$ ), and high bleaching resistance.

\section{Experimental}

To confirm the theoretical propositions, concrete mixes with mechanically activated admixture based on the screenings of crushed concrete has been developed. The composition of admixture include spoly carboxy latesuperplasticizer, micro silica, iron oxide pigment and crushed concrete fines with an average grain size less than 0,063 mother design of concrete mixes was calculated according to high performance concrete design methods[13-17]. Before experiment, available admixtures for use with high-performance decorative concrete were analyzed. As super plasticizers, three types of polycarboxylate superplasticizers (Neoplast, Polyplast SP HPC and Glenium 51) as well as traditional naphthalene sulphonicplasticizer C-3 were chosen for experiment.LanxessBayferrox iron oxide pigment was chosento obtain color characteristics. Crushed concrete fines were obtained from crushed concrete, generated as a result of demolition of load carrying structures of buildings.

Concrete mixes were tested to evaluate their workability, freeze-thaw resistance and unit elongation during freezing and thawing, porosity and water absorption, compressive strength and water resistance. All of the properties were determined on the samples with dimensions of $10 \times 10 \times 10 \mathrm{~cm}$ according to EN and GOST codes and standards [18]. The experiment was made on the equipment of Moscow State University of Civil Engineering.

Standard samples of designed concrete were tested according the GOST methodic to find out the strength, porosity and capillary suction process, as well asdilatometric studies of samples based on the mechanically activated coarse aggregates. The components were 
introduced in two stages: micro silica, crushed concrete fines and pigment were added to the cement prior to mechanochemical activation, plasticizer was added to the mixing water. Mechanochemical activation was carried out using an activator with an annular working chamber. The main feature of this type of activation device is the collision type: the particles in the vortex are subjected to collide at a velocity $\sim 80 \mathrm{~m} / \mathrm{s}$. Initial tests were carried out for concrete mixes based on inactivated coarse aggregate. Compositions of these mixes are shown in Table 1.

Table 1 Mix design of high-performance decorative concrete

\begin{tabular}{|c|c|c|c|c|c|c|c|}
\hline Mix design & B30 & B35 & B40 & B45 & B50 & B60 & B70 \\
\hline Binder/water ratio & 1.92 & 2.14 & 2.39 & 2.64 & 2.83 & 3.3 & 3.77 \\
\hline Cement, $\mathrm{kg} / \mathrm{m}^{3}$ & 383 & 428 & 478 & 529 & 565 & 660 & 754 \\
\hline $\begin{array}{c}\text { Volume concentration of } \\
\text { cement in water-cement paste }\end{array}$ & 0.33 & 0.36 & 0.39 & 0.42 & 0.44 & 0.5 & 0.55 \\
\hline $\begin{array}{c}\text { Micro silica and crushed } \\
\text { concrete fines, } \mathrm{kg} / \mathrm{m}^{3}\end{array}$ & 112 & 102 & 94 & 77 & 73 & 32 & 0 \\
\hline Cement after, $\mathrm{kg} / \mathrm{m}^{3}$ & 271 & 326 & 384 & 452 & 492 & 628 & 754 \\
\hline Absolute volume of aggregate & 664 & 651 & 636 & 621 & 609 & 584 & 557 \\
\hline Coarse aggregate, $\mathrm{kg} / \mathrm{m}^{3}$ & 868 & 851 & 832 & 812 & 796 & 763 & 728 \\
\hline Fine aggregate, $\mathrm{kg} / \mathrm{m}^{3}$ & 868 & 851 & 832 & 812 & 796 & 763 & 728 \\
\hline Compressive strength, MPa & 38.6 & 44.9 & 51.4 & 58.8 & 64.3 & 77.1 & 90.0 \\
\hline Porosity, $\%$ & 13.7 & 13.5 & 13.4 & 13.0 & 12.8 & 12.2 & 11.2 \\
\hline
\end{tabular}

Initial tests have shown (Table 2), that the concrete mixes suits the requirements of compressive strength and workability, but they does not meet the requirements for highperformance concrete frost resistance (it was less than 400 cycles).

Table 2 Main properties of high-performance decorative concrete based on unactivated coarse aggregate

\begin{tabular}{|c|c|c|c|c|}
\hline $\begin{array}{c}\text { Mix } \\
\text { design }\end{array}$ & $\begin{array}{c}\text { Compressive strength } \\
\mathrm{R}, \mathrm{MPa}\end{array}$ & Porosity, \% & $\begin{array}{c}\text { Coefficient of water } \\
\text { absorption. }\end{array}$ & $\begin{array}{c}\text { Unit elongation } \\
\varepsilon_{\lim } 10^{-5} \mathrm{~cm}\end{array}$ \\
\hline B40 & 51.4 & 13.4 & 9.92 & 10.2 \\
\hline B45 & 58.8 & 13.2 & 9.0 & 10.5 \\
\hline B50 & 64.3 & 12.8 & 8.41 & 10.4 \\
\hline B60 & 77.1 & 12.2 & 7.84 & 9.6 \\
\hline
\end{tabular}

To improve the properties of developed high-performance concrete, a method of pretreatment of coarse aggregate by complex admixture was used. This admixture consists of microsilica fume and polycarboxylatesuperplasticizer and added to the concrete mix in two steps. At first, part of the mixing water containing silica fume and polycarboxylate super plasticizer is premixed with the coarse aggregate in the mixer and then added to the remaining water and cement.

Concrete samples based on unactivated and activated coarse aggregate after 28 days of normal storage were tested to find out the structure of concrete and properties of their matrix-aggregate contact zones. The samples were split apart ant the concrete from concrete-aggregate contact zones was collected. After that, collected material was disintegrated to powder and examined by differential thermal analysis and X-ray diffraction analysis. The degree of hydration of cement was determined based on the degree of hydration of $\mathrm{C} 3 \mathrm{~S}$. Concrete samples based on activated coarse aggregate were also tested to find out their compressive strength, workability and coefficient of absorption. The 
properties of high-performance decorative concrete based on unactivated coarse aggregate are shown in Table 3.

Table 3Main properties of high-performance decorative concrete based on activated coarse aggregate

\begin{tabular}{|c|c|c|c|c|}
\hline $\begin{array}{c}\text { Mix } \\
\text { design }\end{array}$ & $\begin{array}{c}\text { Compressive strength } \\
\text { R, MPa }\end{array}$ & Porosity, \% & $\begin{array}{c}\text { Coefficient of water } \\
\text { absorption. }\end{array}$ & $\begin{array}{c}\text { Unit elongation } \\
\varepsilon_{\text {lim }} 10^{-5} \mathrm{~cm}\end{array}$ \\
\hline B40 & 66.8 & 13.4 & 8.4 & 8.1 \\
\hline B45 & 70.5 & 13.2 & 7.56 & 8.5 \\
\hline B50 & 77.8 & 12.8 & 6.75 & 8.3 \\
\hline B60 & 91.7 & 12.2 & 6.42 & 8.0 \\
\hline
\end{tabular}

\section{Results and discussion}

Studies have shown that the compressive strength of concrete, obtained by a two-stage activation, increased by $19-23 \%$; water absorption value decreased by $16-20 \%$; and unit elongation of concrete samples during freezing and thawing decreased by $17-20 \%$. All samples had W12 water resistance degree. It was also found, that porosity of all samples was not more than $14 \%$. Thus, developed concrete can better resist the effects of the severe climatic conditions. The results of X-ray diffraction analysis showed a higher amount of calcium carbonate in the concrete in the unactivated coarse aggregate. That could be connected with a loose structure of the contact zone. Analyzing the results of the experiments it can be concluded that the complex admixture, distributed on the surface of the filler, is interacting with calcium hydroxide and alter the type, volume and number of the pores and helps filling the contact zone by cement hydration products.

X-ray diffraction analysis showed that the degree of hydration of the concrete samples on activated coarse aggregate filler was $84 \%$, whereas the hydration degree of concrete on unactivated coarse aggregate was only $73 \%$.

The termograms for each of the samples shows that DTA curve has three main endothermic peaks: at $110-250^{\circ} \mathrm{C}, 490-510^{\circ} \mathrm{C}$ and $760-780^{\circ} \mathrm{C}$. The first peak at $\mathrm{T}=110$ $250^{\circ} \mathrm{C}$ is the deepest, it shows dehydration of ettringite at $\mathrm{T}=140^{\circ} \mathrm{C}$, the removal of adsorbed water and partial recrystallization of gypsum crystals. These processes are accompanied by a weight loss of $7 \%$ for the samples of concrete based on activated coarse aggregate and $4 \%$ for samples of concrete based on unactivate daggregate. This indicates that the degree of hydration of these samples is higher.

Second peak at $\mathrm{T}=490-510^{\circ} \mathrm{C}$ is connected with the presence of $\mathrm{Ca}(\mathrm{OH})_{2}$, which has less significant weight loss in both samples $(0.5 \%$ and $0.75 \%$ respectively) due to dehydration process. Third peak at $\mathrm{T}=760-780^{\circ} \mathrm{C}$ shows dehydration of hydrated calcium silicate. At $\mathrm{T}=820-850^{\circ} \mathrm{C}$ concrete samples with activated coarse aggregate shows exothermic effect of to bermorite presence.

The main task of creating decorative concrete is the creation of high-quality surface that has highly decorative and ornamental properties, persistent over time [19]. The last property ensures a high resistance to destructive surface environmental factors - frost resistance, color resistance, resistance to acids and alkalis and water-resistance. The most significant factor in these properties is the content of the concrete pores, especially capillary pores. The appearance of chipping, bleaching and discoloration at water saturation dramatically reduce the attractiveness of the product.

To overcome the aforementioned defects of the front surface, it is necessary to increase the density of the concrete, and thereby increase its compressive strength [20]. One of the effective ways to solve this problem is the impregnation of high-performance decorative concrete by low viscosity concrete formulations which can be cured in the concrete pores. Such compounds are widely distributed, but they can affect the color characteristics and 
general attractiveness. The developed concrete mixes have a higher density and a smaller number of capillary pores.

The high specific surface area of mechanically activated components allows them to more efficiently participate in cross-linked reactions.

The particles of pigment are also crushed and more evenly distributed over the volume of the mixture. Unreacted cement grains after activation process partially lose their concrete coating and can hydrate as well. Used iron oxide pigments washed out of the dense concrete matrix less intensively. The denser structure of the contact zone between the filler and the matrix enhances the strength of concrete products and thus expands their appliance range. For example, it becomes possible to obtain facial elements of ventilated façade systems based on concrete, which had a thickness of $5 \mathrm{~mm}$ and do not require reinforcement.

The effective application of the developed concrete for small architectural forms elements of the urban environment decoration, landscape architecture and landscape park art- is also possible. These products are subjects of strong aggressive environmental influences and demands high decoration properties. Small architectural forms based on the developed concrete can maintain decorative properties without the usage of protective coatings.

However, the finished products can be processed with water-repellent compositions of different types, provided that preliminary assessment of their impact on color characteristics will be made. The densest concrete structure must be created on the surface of the article, because the quality and smoothness of the surface has a decisive influence on the resistance to weathering and abrasion and is less prone to sticking snow. The use of materials of high decoration in the construction and reconstruction of cities in Siberia and the Russian Far East could improve the comfort of urban areas and the surrounding neighborhoods and increase the investment attractiveness of migration flows in the city [21].Developed concrete designs and products based on them comply with the requirements of the Russian Federation and European standards and can be further improved without decreasing of their strength characteristics.

At the same time, production line of concrete-based high performance materials does not require the development of a fundamentally new technology. This technique is simple and based on existing economically feasible vibration technology, traditionally used for the production of decorative concrete with a set of conventional equipment. Developed materials also could be used directly at worksites in warm periods.

\section{Conclusions}

High-performance decorative concrete-basedmaterials are highly required for the construction of Russia's regions with severe climatic conditions. One of the ways to improve their application range is the integration of recycled concrete waste as aggregate. The usage of crushed concrete fines, as well as microsilica and polycarboxylate superplasticizers could make high performance decorative concrete more frequently used in Russia's northern regions. As results of the study, high performance decorative concrete materialsbased on mechanochemically activated crushed concrete fines and coarse aggregate with compressive strength of not less than $60 \mathrm{MPa}$, porosity in the range of $15 \%$, frost resistance not less than 400 cycles, water resistance not more than $\mathrm{W} 12$ and sufficient color stability, were designed. In further work it seems appropriate to conduct a more detailed study of the influence of various concrete plasticizers and various types of pigments on color characteristics of concrete-based materials. 


\section{References}

1. M.N. Moroz, V.I. Kalashnikov, O.V. Suzdalsev, Mod. Scien. Res.\&Innov. 10(66), 114 (2016).

2. A.A. Zelenskaya, Bull. Med. Int. Conf. 5, 4, 886 (2014)

3. B.A. Bazyma, Colour and psyche (HGAK, Kharkov, 2001)

4. H. Braem,The Psychology of color (AST, Kladez, Astrel, 2009)

5. L. Evangelista, J. de Brito, Eur. J.ofEnv.and Civ. Eng. 2, 18, 129 (2014)

6. J. Marchand, R. Gagner, S. Jacobsen, Can. J.of civ. Eng., 5, 23 , 1070 (1996)

7. O.M. Kuntcevich Concrete with high frost resistance for the Far North construction (Stroiyzdat, Leningrad-Dep, 1983)

8. M.V.A. Florea, H.J.H. Brouwers. 18 Internat.Baustoff. IBAUSIL, (2012)

9. O.Yu. Bazhenova, Tech. Concr., 4 (81), 44 (2013).

10. O.Yu. Bazhenova, S.I. Bazhenova, Adv. of mod. Science, 6, 3, 21 (2016)

11. A.S. Pilipenko 18 Internat.Baustoff. IBAUSIL, (2012)

12. H. Justnes, P.A. Dahl, V. Ronin, J.-E.Jonasson, L. Elfgren, Cem. \& Conc. Compos., 7, 29, 533 (2007)

13. L.I. Dvorkin,Calculated prediction of the properties and design of concrete compositions (INFRA-Engineering, Moscow, 2016)

14. Y.M. Bazhenov, L.A. Alimov, V.V. Voronin, Structure and properties of concrete with nanomodifiers based ontechnogenic waste. (EBS ASV, MGSU, Moscow, 2013)

15. N.I. Makridin, E.V. Korolev, I.N. Maksimova, Pattern formation and the structural strength of cement composites (EBS ASV, MGSU, Moscow, 2013)

16. G.I. Gorbunov, A.D Zhukov, Scientific bases of formation of structure and properties of building materials (EBS ASV, MGSU, Moscow, 2016)

17. A .G. Zotkin, Concrete with effective admixtures (INFRA-Engineering, Moscow, 2014)

18. O.B. Lyapidevskaya E.A. Bezuglova,Concretes. Technical requirements. Methods of testing (EBS ASV, MGSU, Moscow, 2013)

19. A.F. Buryanov, V.V. Krivenko, A.D. Zhukov, Marble and methods of its simulation. (EBS ASV, MGSU, Moscow, 2014)

20. L.I. Dvorkin, O.L. Dvorkin,Special concrete (INFRA-Engineering, Moscow, 2013)

21. V.S. Teodoronsky, E.D. Sabo, V.A. Frolov, Construction and operation of landscape architecture (Publishing Center "Academia", Moscow, 2008) 